\title{
Are there principles of demography? A search for unifying (and hegemonic) themes ${ }^{1}$
}

\author{
William P. Butz*
}

The principles underlying a field of study can provide both internal coherence and external influence. First, in our context of a scientific discipline, principles can lend coherence by explicating how the discipline's various aspects and pieces fit together, and how their total becomes greater than the sum of the parts. Second, a discipline's principles can suggest how its perspectives and findings might contribute to other disciplines, and, even more broadly, to policy analysis and civil discourse. The exporting of hegemony across scientific fields and beyond-a process that can be more aggressive and less friendly than the usual multidisciplinary pursuits-can awaken new passions in adjacent academic fields.

If there are principles of demography that already reflect and provide coherence within our field, is it then possible that the explicit elucidation or even the promotion of these principles abroad adds to the prominence of our science in the academic and policy communities, while enriching other approaches to studying human behavior? Anthropology, economics, geography, psychology, and sociology might be open to the hegemony of demographic perspectives, models, and tools, as unified under a set of principles.

The philosophy and methodology of science, in which my topic modestly sits, has interested Wolfgang Lutz throughout his career. Drawing on his strong academic grounding in history and philosophy, he has recently made the fruitful proposal of partitioning scientific disciplines into identity sciences and intervention sciences, and causality into strong causality and functional causality (Lutz et al. 2017, 1719). The identity sciences, which are generally the humanities, ask 'Who are we?' and 'Where do we come from?' The intervention sciences ask 'How do the most important forces of change in a social system function, so as to predict the future evolution of the system?'

\footnotetext{
*William P. Butz, Senior Research Scholar, World Population Program, IIASA, Laxenburg, Austria Email: william.butz@icloud.com

1 This paper is the lightly edited text of an oral presentation delivered at the Wittgenstein Centre Conference, December 2016 in Vienna.
} 
While strong causality is possible in the natural sciences, functional causality in the social sciences must, following Lutz, establish causality through three essential criteria. First, there must be a strong empirically observed association between the factors studied. Second, there must be a plausible narrative-I might call this a theory-about the mechanism of influence. Third, the other competing mechanisms must fail.

Beyond offering these particular contributions of definition and differentiation, Lutz clearly has a more general fascination with the question of how the various social sciences approach the world. Having an economist next door to his office for three years gave him ample opportunity to elucidate and argue about these distinctions. Lutz's points were always well thought-out, and, against my counterarguments, often distressingly convincing.

Perhaps the search for the principles of demography that lie beneath the surface of what we do at our desks can enable us to usefully distinguish our science from other disciplines, while injecting our perspectives into other approaches to understanding human behavior.

So what is a principle? Here, based on web sources, are three definitions:

- A principle is a fundamental truth or proposition that serves as the foundation for a chain of reasoning.

- A principle is a general scientific statement or theorem that has numerous special applications across a wide field.

- A principle is a big idea that occurs throughout the subject.

The titles of many textbooks contain the word 'principles': Principles of Chemistry, Physics, Archaeology, Mathematics, Demography, Economics, and more. In demography, the titles of at least three textbooks include the word 'principles'. The textbook by Donald Bogue seems to be first (Bogue 1969).

When pulling books from diverse scientific fields from the library stacks, one searches in vain for any explicit principles in most of them. Instead, the authors apparently use the construction 'principles of' to mean 'introduction to'. In the writing of these textbooks, and possibly in the teaching based on these texts, these two constructions have little or nothing to do with each other. As we shall see, in at least one academic discipline most textbooks with titles that refer to 'principles' elaborate actual principles within their pages.

Whether explicitly stated or not, the content, approaches, and findings of some disciplines appear to be based on strong principles:

- In ethics, there appears to be a principle of respect for individuals, which asserts that individuals are to be treated as autonomous agents. To the extent that this principle is accepted, many relationships between individuals, as well as between individuals and the organizations and governments they interact with, are not considered acceptable.

- In science, independent verifiability and, where applicable, informed consent seem to be universal principles. 
- In physics, Bernoulli's principle relating velocity with pressure in a stream of fluid is accepted as a principle.

- In sociology, the proposition that people behave differently in groups than they do as individuals seems to underlie much of the work in the field, distinguishing sociology from several other disciplinary approaches. Another powerful sociological principle appears to be that societies are organized into distinct social units that tell their members what the rules are. A third potential principle of sociology is that any given group of people has characteristics that a single member does not have.

- In statistics, there seems to be a principle that it is possible to know about the whole by examining a small part only.

I have chosen to elevate these general propositions to the high status of principles without having encountered most of them as such in the smatterings of disciplinary literatures I'm familiar with. Economics is the only field of inquiry I have come across that uses an explicit set of principles, and that directly refers to these principles in textbooks and, more generally, in teaching. Here are four prominent principles of economics: ${ }^{2}$

- Incentives matter. This principle states that across all aspects of human behavior behavioral response elasticities are not zero.

- Decision-making occurs at the margin. This principle animates traditional neoclassical price theory.

- Opportunity costs are the costs that matter in making decisions. Thus, for example, it is not the costs of concrete and steel that matter in deciding whether to build a new airport, but the potential payoff of the best available alternative investment, such as building a network of new primary schools.

- The future is discounted relative to the present. A payoff 50 years from now is worth less in making today's decision than the same payoff today.

Many people will ignore or dispute the relevance of these principles of economics. The first principle falls by the wayside whenever policy-makers design a public program expecting a level of effectiveness that ignores the tendency of people everywhere to turn a change in their environment to their own perceived benefit, often at the expense of the outcomes envisioned by the designers. On empirical grounds, some behavioral economists have called into question the middle two principles by arguing that this is not how people actually behave. Moreover, many environmentalists decry the last principle on ethical grounds.

Indeed, explicit disciplinary principles are explicit targets; a successful attack on a general principle does damage to countless propositions that depend on it. This is surely beneficial for the elucidation of general principles, if not for the academics who depend on them for their livelihood.

2 For the elucidation of selected principles of economics, see, for example: Mankiw (2018); Frank et al. (2016); Case et al. (2016). 
I would argue that these principles of economics have been singularly successful in both maintaining disciplinary coherence (not always a good thing) and exporting hegemony to other social sciences-notably, political science, sociology, and geography - and to civil discourse. To the extent that the effect of exporting hegemony has occurred, it may be due less to the stealthy march of economists into these other fields than to the general familiarity of social scientists with the principles of economics. Similarly, in the domain of civil discourse, it is likely that this effect is attributable less to the presence of economists among decision-makers than to the familiarity of policy-makers with economic principles. Indeed, I suspect that the person on the street, who is unlikely to have taken an economics course, is more familiar in a general sense with one or more of the principles of economics than with any of my examples of principles from other disciplines. Somehow, these economic principles have wormed their way into the public consciousness. Their explicit formulation in teaching and broader exposition may be a fundamental reason why.

Now what about demography? Are there principles of demography that lend coherence to the field? If stated, taught, and promulgated explicitly and proactively as unifying principles, might these propositions have some beneficial hegemonic power in other scientific fields and, more broadly, in civil discourse? Here is my affirmative answer in the form of five proffered principles of demography. There may well be others, but this list represents a start.

- The balancing equation. There are only four ways population size changes: birth, death, movement in, and movement out. From this principle arises the distinction between stocks and flows in dimensions more complex than the size of the population-levels of schooling, for example. This distinction between stocks and flows leads to the difference between ratios and rates, the corresponding epidemiological distinction between prevalence and incidence, and the difference between wealth and income in economics. These distinctions are often lost in confused media discussions of such diverse phenomena as migration, education, disease, economic well-being, and public opinion. They flow directly from the principle of the balancing equation.

- Size, composition, and spatial distribution. Ignoring any one of these three fundamental dimensions of any human population can lead to a misunderstanding of patterns over space or time, with undue influence attributed to the dimension(s) included.

- Age, period, and cohort effects. These three effects are closely related conceptually, and are systemically confounded in the real world. Wittgenstein Centre scientists have recently found through survey data that young people in Europe are more likely to identify with Europe than with their country of residence, whereas older people are more likely to identify with their home country than with Europe (Striessnig and Lutz 2016, 305-311). This finding is interesting in itself, and has critically important implications for Europe's future. Is this difference in the data an age effect, a period effect, or a cohort 
effect? If it is an age effect, then the difference will disappear as young people age and become similar to older people today. If it is a period effect, then the difference is attributable to some peculiarity of the week, month, or year the survey was taken, and may disappear the next time the survey questions are asked. But if the difference is a cohort effect that arises from the socialization of people who are now young, then it is likely to persist as this young cohort ages. This means that when the young people of today grow older, they may continue to identify with Europe, and will therefore differ from the older people of today. The causal nature of this difference will matter for the future of Europe. Wittgenstein Centre research suggests that the cohort explanation is the most likely of the three.

More generally, this three-way distinction is a principle with broad applicability. The relationships between these effects are second-nature to demographers, but are, in my experience, difficult for many others to think clearly about. Economists, for example, might benefit from paying more attention to this principle.

- Cohort progression. The principle that important personal characteristics are cohort characteristics, and thus persist in people as they age, underlies much of Lutz's conceptual and empirical research. The persisting effects of schooling and the lifetime propensity to be in good or bad health are two examples of cohort progression.

- Disaggregation. Population means can hide a great deal of important information, and looking at variances may not yield much more insight. The age/sex/education pyramid, widely used by Lutz in analysis and presentation, is a powerful method of disaggregation with possible applications far beyond demography. More broadly, the disaggregation of data is among the first instincts of empirical demographers, much to the benefit of their science. The other social sciences are far less likely to make use of this approach.

These five principles - the balancing equation; age, period, and cohort effects; population size, composition and spatial distribution; cohort progression; and disaggregation-lend coherence to the practice of demographic description and analysis. It is also highly likely that these principles can prove useful in other social sciences, public policy, and civil discourse. These principles seem to be no less unifying within their discipline and no less broadly applicable than those of economics. If economics can be taken as an example, a first and perhaps necessary step to applying these principles more broadly is to distill them as a clear set of principles, based on my suggestions or others; and to elevate them explicitly to their proper role within the science and its teaching and exposition.

\section{Acknowledgments}

I thank Calvin Goldscheider, Fran Goldscheider, Warren Sanderson, and Barbara Torrey for their suggestions on the written paper. I also appreciate the comments of 
Wittgenstein Centre Conference 2016 participants, including Wolfgang Lutz, on the oral presentation. Responsibility for all interpretations, assertions, and suggestions is mine alone.

\section{References}

Bogue, D. J. 1969. Principles of demography. New York: Wiley.

Case, K. E., R. C. Fair and S. E. Oster 2016. Principles of economics, twelfth edition. Upper Saddle River, NJ: Prentice Hall.

Frank, R., B. Bernanke and K. Antonovics 2016. Principles of economics, sixth edition. Homewood, IL: Richard D. Irwin, Inc.

Lutz, W., W. P. Butz, and S. KC (eds) 2017. World population and human capital in the twenty-first century: an overview. Oxford: Oxford University Press.

Mankiw, N. G. 2018. Principles of economics, eighth edition. Boston: Cengage Learning.

Striessnig, E. and W. Lutz 2016. Demographic strengthening of Europe identity. Population and Development Review 42(2): 305-311. 